\title{
Both NR2A and NR2B subunits of the NMDA receptor are critical for long-term potentiation and long-term depression in the lateral amygdala of horizontal slices of adult mice
}

\author{
Tobias Müller, Doris Albrecht, ${ }^{1}$ and Christine Gebhardt \\ Institute of Neurophysiology, Charité-Universitätsmedizin Berlin, CCM, D-10117 Berlin, Germany
}

\begin{abstract}
The lateral nucleus of the amygdala (LA) is implicated in emotional and social behaviors. We recently showed that in horizontal brain slices, activation of NMDA receptors (NMDARs) is a requirement for persistent synaptic alterations in the LA, such as long-term potentiation (LTP) and long-term depression (LTD). In the LA, NR2A- and NR2B-type NMDRs coexist in synapses of LA projection neurons. We assessed the contribution of the two NMDAR subtypes to LA-LTP and LA-LTD in adult mouse brain slices by different induction protocols and by different inputs to LA neurons in the presence of different NMDAR subunit antagonists. In general, our results indicate that both NR2A and NR2B subunits are required for the formation of LA-LTP and LA-LTD. The abolishment or reduction of plasticity changes by these compounds could be due to the reduction in calcium influx via NMDARs. We also show, to our knowledge for the first time, that paired-pulse (40-msec interstimulus interval), low-frequency stimulation of external capsule fibers causes stable LTD. Rather than resulting from exclusive roles of the NMDAR subtypes, the synaptic plasticity response in the amygdala appears to be directed by the pattern of synaptic activation and the used inputs, which recruit the major NMDAR subtypes to variable extents.
\end{abstract}

The lateral nucleus of the amygdala (LA) is the entry point for most inputs into the amygdala (Pitkaenen et al. 1997). The LA is also an essential component of the neural circuitry underlying Pavlovian fear conditioning (LeDoux 2000; Davis and Whalen 2001; Maren 2005; Sigurdsson et al. 2007). Several studies indicate that both fear conditioning-induced neuronal plasticity and long-term potentiation (LTP) at amygdaloid synapses share common mechanisms of induction and expression (McKernan and Shinnick-Gallagher 1997; Rogan et al. 1997). The phenomenon of LTP, a lasting increase in synaptic efficacy following brief, intense activation of afferences terminating on synapses in the LA, has been studied nearly exclusively in coronal brain slices. In coronal slices, synaptic responses were either elicited by stimulation of fibers from the thalamus (Weisskopf et al. 1999; Schafe et al. 2000; Fendt and Schmid 2002; Lee et al. 2002) or the external capsule (EC). The EC contains amygdala afferences from higher-order sensory cortices (De Olmos et al. 1985). In horizontal slices, EC stimulation also activates excitatory afferences from cortical structures and includes afferences from the lateral entorhinal and perirhinal cortex that course through the EC and synapse in the lateral and the basolateral nucleus of the amygdala (von Bohlen und Halbach and Albrecht 2002). Stimulation within the LA also activates local connections within the LA and afferences from other amygdaloid nuclei (von Bohlen und Halbach and Albrecht 2002). The amygdala lacks an elongated structural organization compared to other brain regions (McDonald 1984; Swanson and Petrovich 1998; Faber et al. 2001; Pitkanen et al. 2003) and is therefore not subject to anisotropic conductance (Johnston and Wu 1995; Logothetis and Wandell 2004). As a result, the field potential response in the LA is not solely

'Corresponding author.

E-mail doris.albrecht@charite.de; fax (030) 450-528962.

Article is online at http://www.learnmem.org/cgi/doi/10.1101/lm.1398709. dependent on underlying dendrite alignment, allowing synaptic activity to potentially contribute to the response (Johnson et al. 2008). Field potential recordings have been used extensively in the LA to study monosynaptic plasticity not only in the behaving animal, but also in brain slices (Huang and Kandel 1998; Lamprecht et al. 2006). Studies done in coronal brain slices showed that the use of high-frequency stimulation (HFS) (Li et al. 1998) only induced persistent LA-LTP when an additional depolarization of the cells (Weisskopf et al. 1999) or GABA receptor antagonists was used (Watanabe et al. 1995; Rammes et al. 2000). In contrast, LALTP in horizontal brain slices can be induced either by HFS of ECafferents (Chapman and Bellavance 1992) or of intranuclear fibers (von Bohlen und Halbach and Albrecht 1998a) without adding GABA receptor antagonists. Importantly, we also could induce stable LA-LTP by stimulation of intranuclear afferents in recordings with sharp microelectrodes (Schubert and Albrecht 2008) without adding GABA receptor antagonists and without additional depolarization of the postsynaptic site. Many studies have shown that LTP can be induced in the amygdala. However, only a few studies have indicated that long-term depression (LTD) occurs in neurons within the LA. In horizontal slices, we have shown in both intracellular and extracellular recordings that LTD can be easily induced by stimulation of intranuclear fibers (Kaschel et al. 2004). It has been suggested that LTD, as a usedependent decrease in synaptic strength, may increase the flexibility of neuronal circuits within the amygdala.

We previously showed in rat horizontal brain slices that activation of $\mathrm{N}$-methyl-D-aspartate subtype glutamate receptors (NMDARs) is required for LA-LTP induced either by cortical stimulation (stimulation of external capsule fibers [EC]) or by stimulation of fibers running through the LA (IN) (Drephal et al. 2006). Similar data were found in rat coronal brain slices using thalamic or cortical stimulation (Gean et al. 1993; Bauer et al. 2002; Faber et al. 2005). In most central synapses, activation of 
NMDARs is also required for inducing LTD. However, little is known about how activation of NMDARs leads to these two opposing forms of synaptic plasticity. Induction of LTD requires a relatively small amount of $\mathrm{Ca}^{2+}$ influx through NMDARs (Cummings et al. 1996; Nishiyama et al. 2000). We previously showed that L-type calcium channels (Tchekalarova and Albrecht 2007) and group II mGLURs are involved in the induction of LA-LTD, and that NMDARs are also crucial for the induction of LTD (Kaschel et al. 2004).

NMDARs are heteromers composed of NR1 and NR2 subunits. NR1 subunits, which exist in one of eight splice variants, contain the binding site for the coagonist glycine, whereas four types of NR2 subunits exist, each of which contains a binding site for glutamate (Dingledine et al. 1999; Erreger et al. 2005). Large numbers of individual subunit combinations of NR1 and NR2A-D subunits are possible, each of which could have a different functional role within the synapse or, indeed, outside of it, in the extrasynaptic regions. Combinations of NR1 with one or more of the NR2 subunits generate receptors with functional properties (Kutsuwada et al. 1992). It has been demonstrated that NR2A and NR2B subunits dominate in the forebrain and that the NR2A subunit kinetics are more rapid compared with those of NR2B (Monyer et al. 1994).

Recent work dissecting the role of NR2 subunits in synaptic plasticity indicates that the NR2A subunit is involved in the induction of LTP, whereas the NR2B subunit contributes to the formation of LTD in the hippocampus and cortex (Liu et al. 2004; Massey et al. 2004). The mechanisms underlying amygdala LTP have been studied most extensively in the thalamo- and corticoLA pathways. In these pathways, it has been shown that the NR2B subunit antagonist ifenprodil blocked LA-LTP (Bauer et al. 2002). In addition, systemic injections of ifenprodil before training led to a dose-dependent impairment in the acquisition of auditory and contextual fear conditioning, whereas injections before testing had no effect (Rodrigues et al. 2001). It has been shown recently that blockade of NR2B-containing NMDA receptors impairs fear acquisition while sparing fear expression. Conversely, blockade of NR2A-containing NMDA receptors impairs both fear acquisition and expression (Walker and Davis 2008). However, to our knowledge, no data are available regarding whether NR2A- or NR2Bcontaining NMDARs contribute to the induction of LTD in the LA. Here, we show that NR2A and NR2B are involved in amygdaloid plasticity in a pathway-specific manner, and that both NR2A and NR2B are involved in the induction of LA-LTP and LA-LTD.

\section{Results}

\section{Effects of the NR2A- and NR2B-specific antagonists on input/output curves and PP facilitation}

Examination of the contribution of the NR2B subunit to baseline activity showed that insignificant changes were obtained in input/ output curves when we independently tested Co $101244(1 \mu \mathrm{M})$ and Ro 04-5595 $(10 \mu \mathrm{M})$ in the horizontal brain slices. We stimulated either IN fibers, which also involve afferents from other amygdaloid nuclei (von Bohlen und Halbach and Albrecht 1998 b), or EC fibers, which mainly contain afferents from the entorhinal and perirhinal cortex (Fig. 1A; von Bohlen und Halbach and Albrecht 2002). A typical example of a field potential recorded in the LA is shown on the left side. The amplitudes increase by increasing the current intensities. The observed independence of the input/output curves of the NMDA antagonists is in agreement with our previous results in adult rats (Drephal et al. 2006), which showed that APV did not change the basal transmission. Figure 1B shows that the input/output curves remain uninfluenced by washing-in of the NR2B antagonist. We found similar results using the intranuclear stimulation site (IN) (Fig. 2A). No significant changes in input/output curves were also found with the NR2A-specific antagonist NVP-AAM077 at different concentrations $(0.05 \mu \mathrm{M}, 0.1 \mu \mathrm{M}$, and $0.4 \mu \mathrm{M}$; Figs. $1 \mathrm{C}, \mathrm{D}, 2 \mathrm{~B}-\mathrm{D})$.

Next, we studied the effect of NR2B subunit antagonists on PPF. PPF is thought to be a presynaptic process but is also dependent on inhibitory mechanisms (Zinebi et al. 2001). In the presence of Co $101244(1 \mu \mathrm{M})$ and Ro 04-5595 (10 $\mu \mathrm{M})$, PPF was unchanged using either the IN or the EC stimulation site (Figs. 1E, $2 \mathrm{E})$. These results suggest that these drugs do not affect glutamate release, at least not in adult mice. In the presence of NVP-AAM077 at different concentrations, PPF was also not changed significantly (see, e.g., Figs. 1F, 2F). These results are also in accordance with findings in adult rats, in which APV did not influence PPF (data not shown).

\section{Both NR2A and NR2B subunit antagonists decrease isolated NMDAR EPSCs}

Since other authors described an influence of NR2A and/or of NR2B subunits on baseline activity (Shin et al. 2006), we performed additional recordings in the whole-cell patch-clamp mode. We recorded whole-cell NMDAR EPSCs in the presence of the $\alpha$-amino-3-hydroxy-5-methyl-4-isoxazolepropionic acid receptor (AMPAR) antagonist 6-cyano-7-nitroquinoxaline-2,3-dione $(\mathrm{CNQX}, 20 \mu \mathrm{M})$ at a holding potential of $+40 \mathrm{mV}$ to relieve the $\mathrm{Mg}^{2+}$ block of NMDAR channels. In horizontal slices derived from adult male mice in the presence of $0.05 \mu \mathrm{M}$, as well as of $0.1 \mu \mathrm{M}$ NVP-AAM077, isolated NMDAR EPSC declines in the course of repetitive presynaptic EC stimulation $(0.1 \mathrm{~Hz})$ (Fig. 3A,C). NVPAAM077 $(0.05 \mu \mathrm{M})$ moderately reduced the magnitude of the NMDAR EPSC by $24.5 \% \pm 5.0 \%(n=4)$ of its baseline value. The increase in NVP-AAM077 concentration $(0.1 \mu \mathrm{M})$ induced a stronger reduction of NMDAR EPSCs. Subsequent addition of D-APV $(50 \mu \mathrm{M})$ nearly completely blocked the NMDAR EPSC $(81.7 \% \pm$ $1.7 \%$ reduction, $n=4$; Fig. $3 \mathrm{E}$ ). To analyze the effect of NR2B blockade, we used ifenprodil to get a comparison to the recent data obtained in the LA in juvenile coronal slices (Shin et al. 2006). Application of ifenprodil $(10 \mu \mathrm{M})$ depressed the isolated NMDAR EPSC recorded in the presence of CNQX at a holding potential of $+40 \mathrm{mV}$. In the presence of the NR2B antagonist ifenprodil, the NMDAR EPSC was reduced by $46.6 \% \pm 7.1 \%(n=4)$ of its baseline value (Fig. 3B,D). Subsequent addition of D-APV $(50 \mu \mathrm{M})$ increased the suppression of NMDAR EPSCs (reduction by $79.6 \% \pm 3.2 \% ; n=4)$. These results show that the effect of NR2B subunits on baseline activity seems to be stronger than that of NR2A subunits.

\section{Both NR2A and NR2B subunits are involved in the induction of LA-LTP}

We used the IN stimulation site to induce LA-LTP, and then we tested two different NR2B subunit antagonists. As shown in Figure 4, A and C, both NR2B antagonists provoked a reduction in LA-LTP (control: $145.3 \% \pm 7.2 \%[n=6]$ vs. $10 \mu \mathrm{M}$ Ro 04-5595: $121.9 \% \pm$ 5.2\% $[n=7]$ and $1 \mu \mathrm{M}$ Co 101244: $119.1 \% \pm 6.1 \%[n=8] ; P=$ 0.03). The effects of Ro 04-5595 and Co 10244 did not differ significantly. In the presence of NVP at different concentrations (Fig. 4B), the amount of LTP suppression induced by NVP did not differ (control: $151.8 \% \pm 6.7 \%[n=7]$ vs. $0.1 \mu \mathrm{M} \mathrm{NVP:} 127.5 \% \pm$ $2.5 \%[n=7]$ and $0.4 \mu \mathrm{M}$ NVP: $125.1 \% \pm 4.1 \%[n=12])$.

In summary, because HFS-triggered LA-LTP is reduced but not blocked in the presence of NR2A or NR2B subunit antagonists, more than one subtype seems to be involved during induction.

To further substantiate that both NMDAR subtypes are capable of inducing LTP, further experiments were carried out with EC stimulation in the presence of NR2B antagonists. Figure 4, 
A

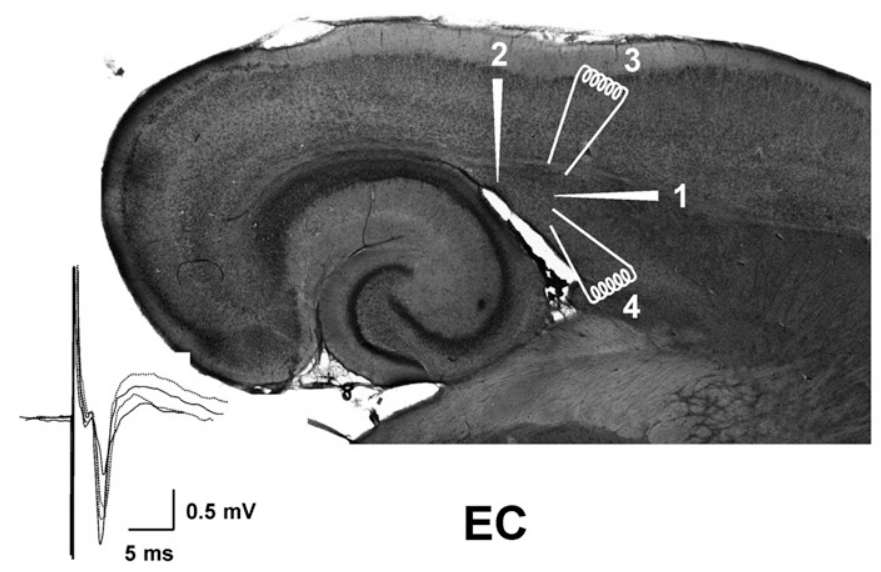

B
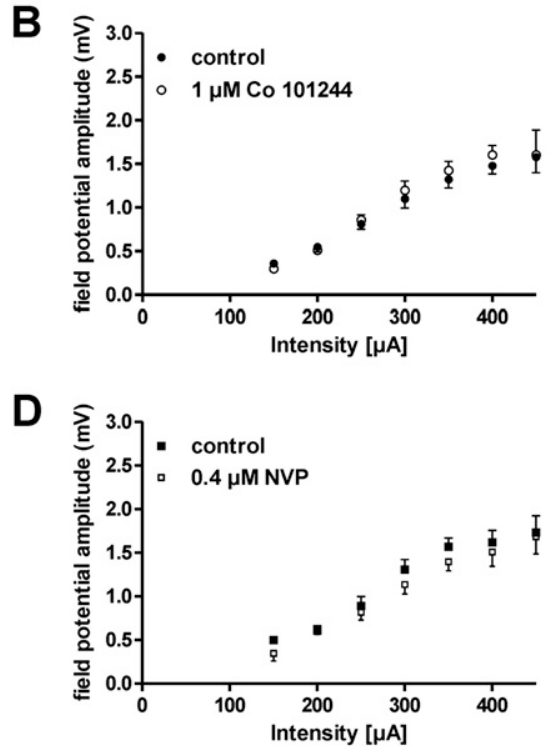

$\mathbf{F}$

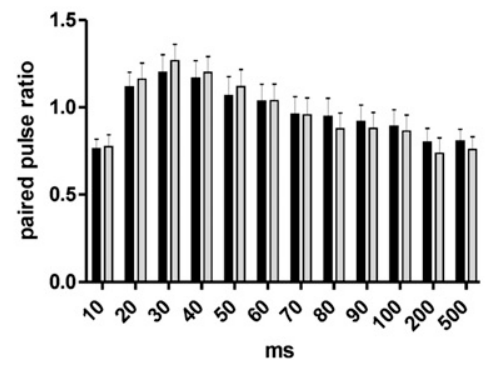

Figure 1. Basal excitability and paired-pulse facilitation induced by stimulation of fibers running through the external capsule (EC). (A) Example of a rodent brain horizontal section. Location of recording ( 1 and 2 ) and stimulation electrodes (EC, 3; within the LA, 4) are schematically shown. If EC stimulation was used, then field potentials could be easily recorded in position 1 . If the IN site was used then the recording electrode was always located in the dorsoventral part of the LA (2). If both stimulation sites were used in one slice, the position of the recording electrode was frequently located in position 1. On the left site a representative example of original traces of a field potential recorded in the LA is shown (six averages). The amplitude of field potentials increases with increasing current intensity. (B) EC-induced input/output curves recorded in drug-free conditions and in the presence of $1 \mu \mathrm{M} \mathrm{Co}$ $101244(n=10)$. $(C, D)$ Input/output curves before and after application of $0.4 \mu \mathrm{M}(n=9)$ and $0.05 \mu \mathrm{M}$ NVP-AAM077 $(n=12)$, respectively $(P \geq 0.05)$. (E) PP facilitation of the same sample of recordings (black columns) before and (white columns) after wash-in of Co $101244(P \geq 0.05)$. ( $F)$ PPF (black columns) before and (gray columns) after application of $0.05 \mu \mathrm{M}$ NVP. PP ratio: The relationship of the second-response amplitude with respect to the first-response amplitude was calculated and plotted as the PP ratio against the interstimulus interval. X-axis, interstimulus interval; EC, External capsule stimulation.
$\mathrm{D}$ and $\mathrm{F}$, demonstrates that LTP was still induced in the presence of $1 \mu \mathrm{M}$ Co 101244; however, the magnitude of LALTP was significantly reduced (control: $153.3 \% \pm 7.2 \%[n=7]$ vs. Co $101244:$ $118.4 \% \pm 11.6 \%[n=10] ; P=0.03$; Fig. $4 \mathrm{D})$. This result correlates with recent data showing that the NR2B antagonist ifenprodil is able to suppress LA-LTP induced by cortical or thalamic stimulation in rat coronal brain slices (Bauer et al. 2002). Next, we investigated the role of the NR2A subunit in the formation of ECinduced LA-LTP. Blockade of the NR2A subunit with NVP also caused a reduction in LTP magnitude (control: $149.5 \% \pm$ $5.7 \%[n=7]$ vs. $0.05 \mu \mathrm{M}$ NVP: $139.5 \%$ $\pm 8.7 \%[n=11]$ and $0.4 \mu \mathrm{M}$ NVP: $128.8 \%$ $\pm 10.4 \%[n=10] ; P=0.03$; Fig. $4 \mathrm{E})$. The different drug-free controls did not differ significantly. Moreover, the effects of used NMDA subunit antagonists did not differ significantly when we compared IN versus EC stimulation site.

Therefore, our results indicate that both NR2A and NR2B subunits are required for the formation of LA-LTP, independent of the afferents that were used. Figure 4F shows that the effect of the NR2B blockade on the magnitude of LA-LTP appeared to be stronger than that of NR2A, at least when the cortical fibers were stimulated.

\section{NR2A and NR2B subunits are involved in the induction of LA-LTD}

It is known that inhibitory mechanisms in horizontal slices are weaker than in coronal slices (Samson et al. 2003; Samson and Pare 2006). This could account for the fact that we can induce LA-LTD by IN-LFS in both intracellular and extracellular recordings in adult rats (Kaschel et al. 2004) and mice (Tchekalarova and Albrecht 2007), whereas the LFS of the EC pathway did not result in LA-LTD.

To analyze the involvement of NR2B subunits in the induction of LFS-induced LA-LTD, we stimulated IN fibers in the presence of $1 \mu \mathrm{M}$ Co 101244. As shown in Figure 5A, LTD was not completely blocked by the NR2B antagonist, but was significantly weaker than in drug-free control recordings (control: $76.6 \% \pm$ $4.1 \%[n=8]$ vs. $1 \mu \mathrm{M}$ Co $101244: 88.3 \%$ $\pm 4.5 \%[n=11] ; P=0.03)$. Although LALTD was still induced in the presence of the NR2B antagonist, it was abolished at $0.4 \mu \mathrm{M}$ and at $0.1 \mu \mathrm{M}$ NVP (control: $83.9 \% \pm 4.5 \%[n=11]$ vs. $0.1 \mu \mathrm{M}$ NVP: $95.9 \% \pm 2.3 \%[n=10]$ and $0.4 \mu \mathrm{M}$ NVP: $95.3 \% \pm 4.8 \%[n=16] ; P=0.03$; Fig. $5 \mathrm{~B}, \mathrm{C})$. 


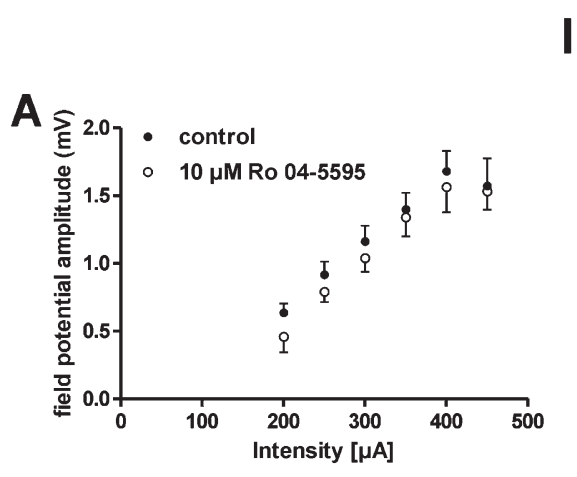

\section{IN}
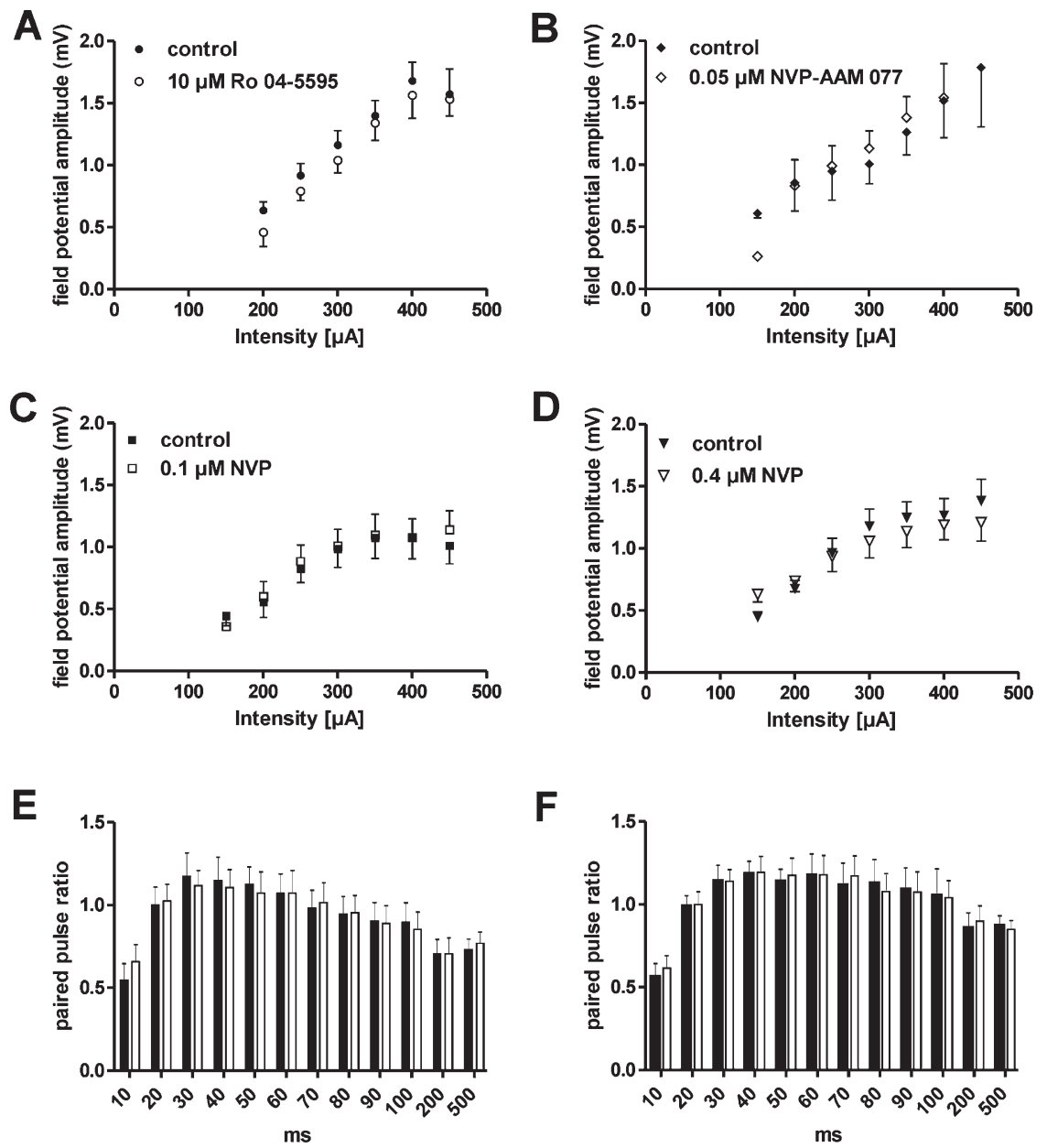

Figure 2. Basal excitability and paired-pulse facilitation induced by stimulation of fibers running within the LA (IN). (A) IN-induced input/output curves recorded in drug-free conditions and in the presence of $10 \mu \mathrm{M}$ Ro 04-5595 $(n=18) ; P \geq 0.05$. (B-D) Input/output curves before and after application of $0.05 \mu \mathrm{M}(n=10), 0.1 \mu \mathrm{M}(n=14)$, or $0.4 \mu \mathrm{M}$ NVP-AAM077 $(n=30), P \geq 0.05$. (E) PP facilitation of the same sample of recordings (black columns) before and (white columns) after wash-in of $10 \mu \mathrm{M}$ Ro $04-5595, P \geq 0.05$. ( $F$ ) PPF (black columns) before and (white columns) after application of NVP. PP ratio: The relationship of the second response amplitude with respect to the first response amplitude was calculated and plotted as the PP ratio against the interstimulus interval. $X$-axis: interstimulus interval.

To test whether EC stimulation and IN stimulation activated two independent pathways, we delivered paired pulses to the two stimulation sites (one pulse to IN, $5 \mathrm{sec}$ later the other to EC) and compared the results. The successive application of LFS caused a persistent LA-LTD in the IN pathway, whereas single-pulse LFS of EC fibers provoked a late LA-LTP (IN: $77.7 \% \pm 7.1 \%$ vs. EC: $124.6 \% \pm 8.7 \% ; n=8$; Fig. $5 \mathrm{E}$ ). A late EC-induced LA-LTP in response to low-frequency stimulation of EC fibers was described previously in coronal slices (Huang and Kandel 2007). These results show that $\mathrm{EC}$ and IN stimulation activate different afferents to the LA. Similar results were found in the BLA of coronal slices (Aroniadou-Anderjaska et al. 2001).

Prolonged repetitive synaptic stimulation at $1 \mathrm{~Hz}$ is a typical protocol for inducing LTD in the brain. However, in the adult brain, LFS is less effective at inducing LTD (Wagner and Alger 1995; Norris et al. 1996). To induce a higher rate of calcium entry postsynaptically, we tested paired-pulse low-frequency stimulation (PP-LFS) with different interstimulus intervals (ISI); this is known to be a reliable stimulation protocol in the hippocampus of adult animals (Kemp and Bashir 1999). We tested different paired-pulse (PP) intervals of low-frequency stimulation of fibers within the LA: 30, 40, and $60 \mathrm{msec}$. Whereas ISIs from $30-40$ msec provoke a reliable and persistent reduction of field potential amplitudes (30 msec: 90.6\% \pm $4.6 \%[n=9] ; 40$ msec: $82.7 \% \pm 4.9 \%[n=$ $8]$ ), the interval of $60 \mathrm{msec}$ resulted in insignificant changes in field potential amplitude $1 \mathrm{~h}$ after LFS, in comparison with pre-LFS levels $(101.2 \% \pm 4.3 \%[n=$ 10]; see also Fig. 6A).

To test whether the involvement of NR2A and NR2B subunits in LA-LTD induction is dependent on the induction protocol, we next applied PP-LFS to IN fibers with an ISI of $40 \mathrm{msec}$ during drug application. Using this protocol in the presence of $10 \mu \mathrm{M}$ Ro 04-5595, LA-LTD did not differ significantly from drug-free control recordings (control: 82.7\% \pm $4.9 \%[n=8]$ vs. $84.5 \% \pm 5.8 \%[n=8] ; P$ $\geq 0.05$; Fig. 5D). In contrast, in the presence of $0.05 \mu \mathrm{M}$ NVP, LA-LTD was significantly reduced by PP-LFS $(0.05 \mu \mathrm{M}$ NVP: $91.0 \% \pm 2.6 \%[n=10] ; 0.4 \mu \mathrm{M}$ NVP: $94.8 \% \pm 5.2 \%[n=11] ; P=0.03$; Fig. $5 \mathrm{D})$. There was no difference in the effects on field potential amplitude between the two concentrations of NVP. Thus, as summarized in Figure 5, C and $\mathrm{D}$, the NR2A antagonist seemed to have a stronger effect on the induction of LALTD when IN fibers were stimulated.

To our knowledge, EC-induced LALTD has not been demonstrated previously. After single-pulse, low-frequency stimulation of IN and EC afferents, we could record LTD in response to stimulation of fibers running through the LA, whereas simultaneously in response to EC stimulation LA neurons developed a late LTP (Fig. 5E). Therefore, we tested PP-LFS of EC-fibers to prove whether this protocol will be suited to induce LA-LTD. As shown in Figure 5F, EC-induced PP-LFS with an interstimulus interval of $40 \mathrm{msec}$ induced stable LA-LTD. This persistent decrease in field potential amplitude was completely blocked in the presence of $10 \mu \mathrm{M}$ Ro $04-5595$ (control: $77.8 \% \pm 4.2 \%$ [ $n=9]$ vs. Ro 04-5595: $121.3 \% \pm 6.4 \%[n=7] ; P<0.03)$. Blockade of the NR2A subunit with NVP also abolished LA-LTD $(0.1 \mu \mathrm{M}$ NVP: $101.8 \% \pm 2.6 \%[n=5], 0.4 \mu \mathrm{M}$ NVP: $111.9 \% \pm 6.6 \%[n=7]$; Fig. $5 \mathrm{G}, \mathrm{H})$. Thus, PP-LFS administered in the presence of either NR2Aor NR2B-subtype-specific antagonists fails to reveal a preferred NMDAR subtype for LA-LTD induction.

In addition, we observed that PPF was increased $1 \mathrm{~h}$ after LFS in comparison with pre-LFS PPF (40 msec ISI: $P=0.001 ; 30 \mathrm{msec}$ ISI: $P=0.0005$; Fig. $6 \mathrm{~B}, \mathrm{C}$ ), suggesting a presynaptic involvement in LA-LTD induction. It should be noted that changes in PPF were not significant $1 \mathrm{~h}$ after HFS (data not shown).

Taken together, our results indicate that both NR2A and NR2B subunits are required for the formation of LA-LTP and LALTD, and that the abolishment of plasticity changes by these 


\section{EC}

A
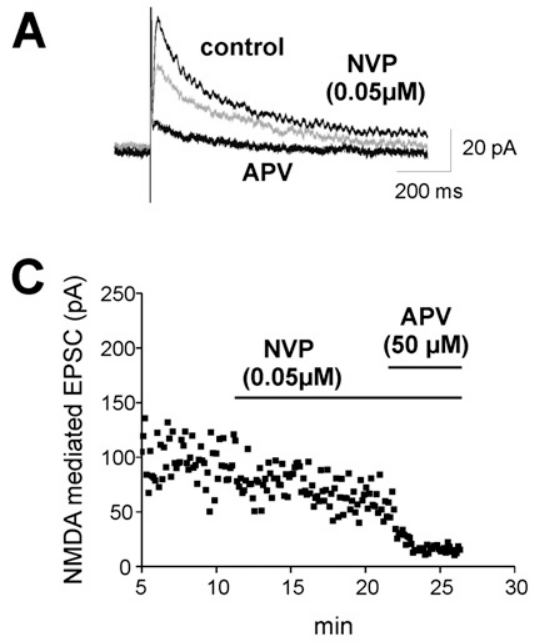

B

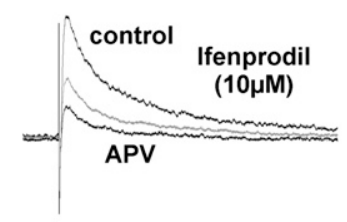

D

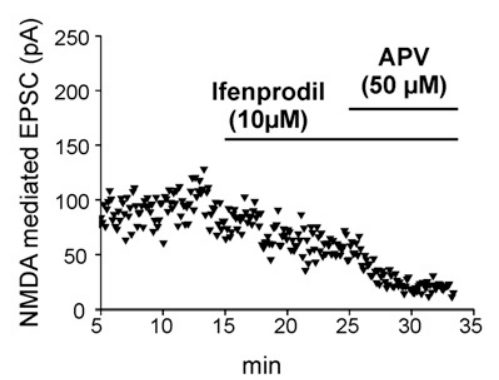

E

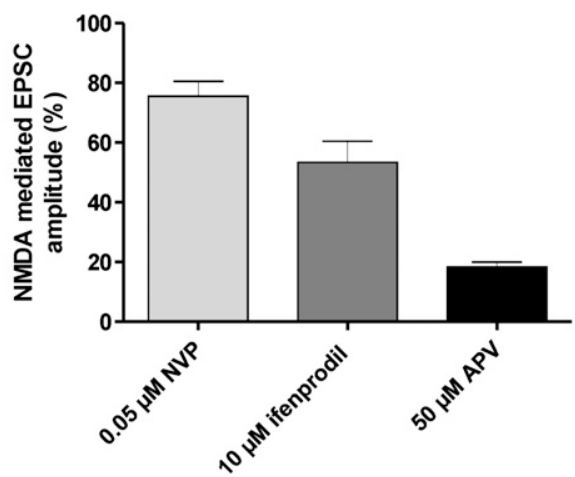

Figure 3. NR2A and NR2B subunits contribute to the evoked EPSC induced by EC stimulation. (A) Representative responses of a LA pyramidal neuron to repetitive $(0.1 \mathrm{~Hz})$ EC stimulation under control conditions, in the presence of NVP $(0.05 \mu \mathrm{M})$ and after application of APV $(50 \mu \mathrm{M})$ recorded at $+40 \mathrm{mV}$ (B) Representative responses of a LA pyramidal neuron to repetitive $(0.1 \mathrm{~Hz})$ EC stimulation under control conditions, in the presence of ifenprodil $(10 \mu \mathrm{M})$ and after application of APV $(50 \mu \mathrm{M})$ recorded at $+40 \mathrm{mV}$. The mean amplitude under control conditions was $78 \pm 7 \mathrm{pA}(n=7)$. Current and time calibration at $A$ also applied to $B$. (C) Time course of NMDA-mediated EPSC amplitude under control conditions, after bath application of $0.05 \mu \mathrm{M}$ NVP and subsequent bath application of $50 \mu \mathrm{M}$ APV. (D) Time course of NMDA-mediated EPSC amplitude under control conditions, after bath application of 10 $\mu \mathrm{M}$ ifenprodil and subsequent bath application of $50 \mu \mathrm{M}$ APV. (E) Histogram showing the effect of NMDA receptor subunit blockade. EPSC amplitudes were reduced by NVP $(0.05 \mu \mathrm{M})$ and ifenprodil $(10 \mu \mathrm{M})$.

compounds could be due to a reduction in calcium influx via NMDARs.

\section{Discussion}

Using whole-cell voltage-clamp recordings from pyramidal neurons of the LA at room temperature, we show that both NR2A- and NR2B-subunit-containing NMDARs are functionally expressed at cortico-amygdala synapses not only in coronal slices derived from juvenile rats (Shin et al. 2006) but also in horizontal slices derived from adult mice. Addition of the selective NR2A antagonist NVPAAM077 also in a highly specific concentration of $0.05 \mu \mathrm{M}$ as well as of the selective NR2B antagonist ifenprodil $(10 \mu \mathrm{M})$ to the external solution produced progressive decreases in the amplitude of the isolated NMDAR EPSC recorded at a holding potential of $+40 \mathrm{mV}$ in the presence of CNQX and bicuculline at least in the cortical pathway. The stronger decrease in NMDAR EPSC in the presence of $0.5 \mu \mathrm{M}$ NVP-AAM077 might be due to the higher concentration used in the study of Shin et al. (2006), which partly also may block NR2B subunits of the NMDA receptor. In addition, it has been demonstrated in whole-cell patchclamp recordings in coronal mice brain slices that ifenprodil significantly inhibited NMDA EPSCs in principal LA cells induced by thalamic stimulation (Miwa et al. 2008). AMPA and NMDA receptor-mediated responses were shown to coexist at different inputs to the LA (Mahanty and Sah 1999; Weisskopf and LeDoux 1999). In contrast to our patchclamp recordings and other results in coronal slices also obtained in patchclamp recordings (Mahanty and Sah 1999; Weisskopf and LeDoux 1999), we did not find significant changes in $\mathrm{I} / \mathrm{O}$ curves in the presence of NR2A or NR2B antagonists in extracellular recordings. Extracellular recordings were performed under nearly the same experimental conditions as patch-clamp recordings (horizontal slice, same age, same stimulation electrodes). However, in field potential recordings, AMPA and kainate receptors were not blocked. The single-pulse stimulation in extracellular recordings does not seem to be able to release $\mathrm{Mg}^{2+}$ blockade. As expected in coronal slices at the resting membrane potential, EPSPs evoked either the EC or thalamic inputs were unaffected by application of the NMDA receptor antagonist APV (Mahanty and Sah 1999). In extracellular recordings, we have not observed any NMDAR involvement in basal LA transmission in adult rats (Drephal et al. 2006). The lack of any effects of the NMDAR antagonist APV on normal synaptic transmission in the LA of adult rodents has also been observed in coronal slices during EC stimulation (Huang and Kandel 1998; Schroeder and ShinnickGallagher 2004). Therefore, the degree of NMDAR involvement in basal transmission might be explained not only by differences in which inputs are stimulated, by species differences, or in experimental paradigms such as temperature, but rather by the methods used. In all patch-clamp recordings, the blockade of the NMDA receptor by $\mathrm{Mg}^{2+}$ is removed by the positive holding potential.

Since we did not find changes in PP facilitation in the presence of NR2A or NR2B subunit antagonists, the presynaptic involvement in mediation of plasticity changes as shown recently (Tsvetkov et al. 2002; Humeau et al. 2003) owing to the existence of presynaptic NMDARs (Farb et al. 1995) seems to play a smaller role in adult rodents.

Using a pharmacological approach, our results also show that LTP and LTD induction at lateral amygdala synapses does not require a particular NMDAR subtype. However, our results, which were obtained using different LTD induction protocols, also reveal that there exists, to a certain degree, an input specificity. In the presence of NR2B subunit antagonists, EC-induced LA-LTD was 
IN

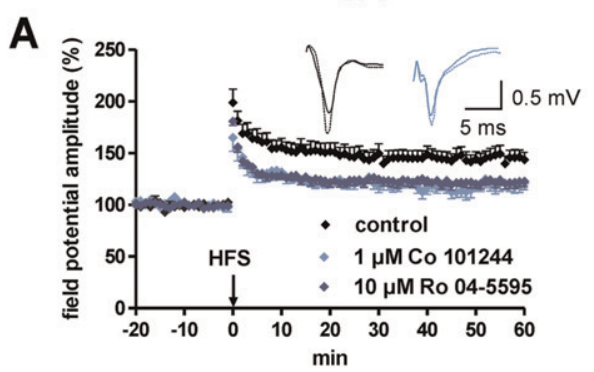

B

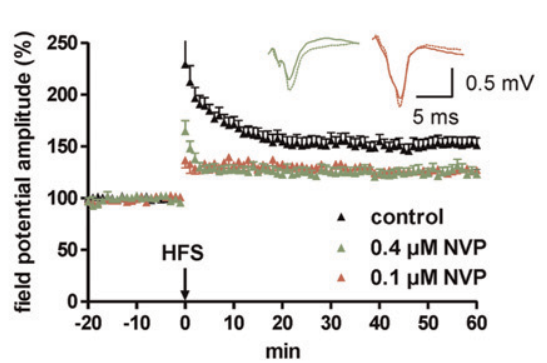

C

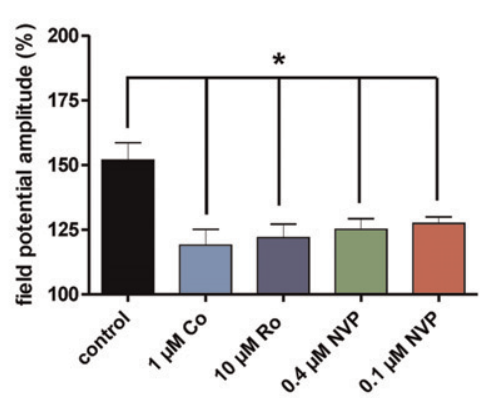

EC

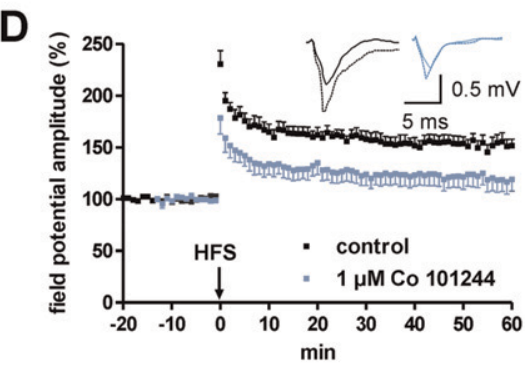

E

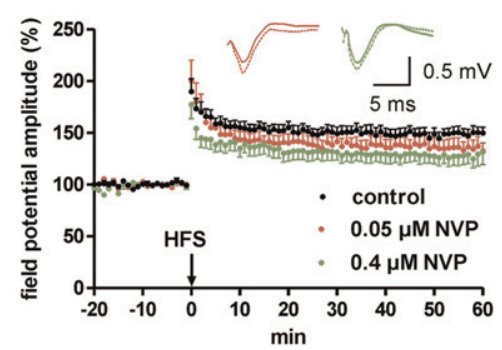

$\mathbf{F}$

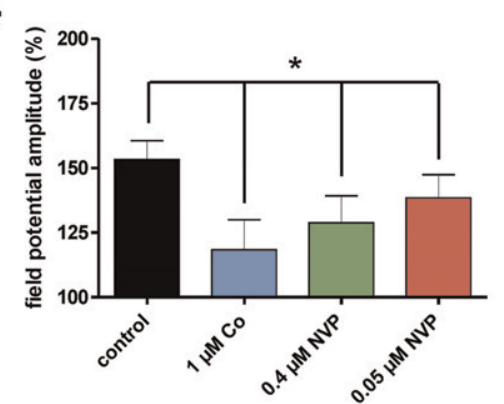

Figure 4. NR2A and NR2B subunits are involved in the induction of LA-LTP. IN stimulation caused a reduction in the magnitude of LA-LTP in the presence of different NR2B subunit antagonists $(A)$ and in the presence of NR2A subunit antagonist NVP at different concentrations $(B)$. Recordings in $D$ and $E$ were performed during stimulation of EC fibers. $(D)$ In the presence of the NR2B subunit antagonist Co 101244, the magnitude of LA-LTP was reduced compared with drug-free controls. $(E)$ Low concentrations of NVP suppress LA-LTP to a lower extent than do higher concentrations, when compared with controls. (HFS) High-frequency stimulation. Data points represent averaged amplitudes (mean \pm SEM) normalized with respect to baseline values. Representative traces were recorded (solid lines) 5 min prior to tetanus and (dashed lines) $60 \mathrm{~min}$ after tetanus in the lateral nucleus of the amygdala. $(C, F)$ Bar histograms of data points averaged 57 to $60 \mathrm{~min}$ after HFS and normalized with respect to baseline (mean \pm SEM). Significant differences are indicated. ${ }^{*} P \leq 0.05$.

completely blocked, whereas using the same induction protocol, stimulation of fibers within the LA LTD was dependent to a greater extent on NR2A NMDARs. In contrast, using different inputs to LA neurons, LTP induction was not prevented by the NR2A- and NR2B-specific antagonists. Similar results were described in young mouse hippocampal slices (Berberich et al. 2005; Bartlett et al. 2007) and in the anterior cingulated cortex (Zhao et al. 2005). Our findings that NR2B-type NMDARs are involved in the induction of LTP are consistent with those obtained in genetically modified mice, in which NR2B expression was up-regulated (Tang et al. 1999; Wong et al. 2002) or NR2A signaling was impaired (Kiyama et al. 1998; Kohr et al. 2003). Our findings also correspond to results found in coronal slices of the lateral amygdala, in which stimulation of thalamic and/or cortical fibers in the presence of ifenprodil did not elicit LA-LTP (Bauer et al. 2002; Miwa et al. 2008). In addition, we have shown, for the first time to the best of our knowledge, that NR2A subunits are also involved in the induction of LA-LTP. Since NVP-AAM $(0.5 \mu \mathrm{M})$ had no effect on spike timing-dependent LTP at amygdala synapses (Shin et al. 2006), the involvement of NMDA NR2A subunits seems to depend on LTP induction paradigms. Thus, LA-LTP elicited by HFS in adult mice appears to involve more than a single NMDAR subtype. In contrast, LTP induction in $N R 2 A^{-/-}$mice relies solely on NR1/NR2B receptors and requires repeated tetanization (Sakimura et al. 1995; Kiyama et al. 1998).

The first study to document LA-LTD in coronal slices of the lateral amygdala (Heinbockel and Pape 2000) used thetapulse stimulation (TPS) (8 Hz for $150 \mathrm{sec}$ ) of thalamic input fibers. This stimulation resulted in LA-LTD in 21\% of the tested neurons. We found that TPS of afferents within the LA caused a weaker LTD in horizontal slices than did low-frequency stimulation (900 pulses, $1-\mathrm{Hz}$ LFS) (Schubert et al. 2005). We have shown in the present study that LA-LTD cannot be induced by using single-pulse LFS of EC fibers. This result has been also documented previously in horizontal slices derived from rats or mice (Kaschel et al. 2004; Tchekalarova and Albrecht 2007) or in coronal brain slices (Heinbockel and Pape 2000). It is most likely due to inadequate protocols and not to a reduced ability for decreased synaptic transmission. It is known that EC fibers innervate GABAergic interneurons besides projection neurons, and NR2B subunits contribute to NMDA receptor-mediated responses associated with thalamic and cortical input fibers not only in projection neurons but also in LA GABAergic interneurons (Szinyei et al. 2003). The cortical innervation of GABAergic interneurons seems to be stronger in comparison with intranuclear stimulation sites. Thus, projection neurons may be slightly more hyperpolarized by low-frequency EC stimulation, with no relief of the $\mathrm{Mg}^{2+}$ block of NMDAR, as would be the case during LFS of IN fibers. The present results show that by using PP-LFS of EC fibers with an interstimulus interval of $40 \mathrm{msec}$, LA-LTD can be provoked. PP-LFS seemed to cause a higher increase in intracellular calcium, thereby facilitating the induction of LA-LTD. A partial restriction of the NR2B pathway after PP-LFS became only evident when cortical fibers running through the external capsule were stimulated, which gave the NR2B-subtype an advantage over NR2A. Recently it has been shown that NR2A- and NR2B-subunit antagonists block LTD in cingulated neurons (Toyoda et al. 2005).

LTD within the amygdala could enhance the relative effect of LTP at neighboring synapses by increasing the signal-to-noise ratio, as shown recently in the amygdala (Royer and Pare 2003). The true role of LTD in the amygdala remains to be determined. It might be an adaptive response in which stress or anxiety resets previously induced plastic changes to facilitate the generation of new information through LTP (Diamond et al. 2005). Taken together with recent evidence that extrasynaptic spillover of glutamate is detected exclusively by NR2B-containing NMDARs 
A

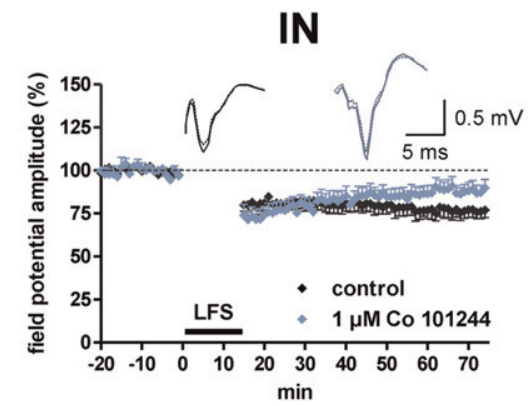

B

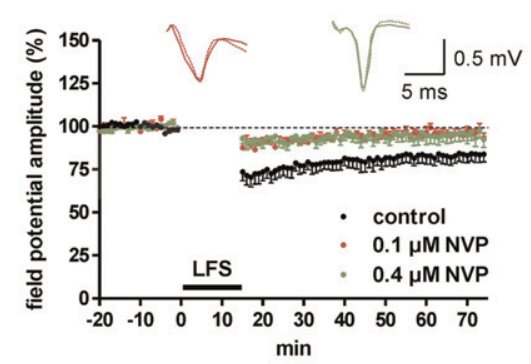

C

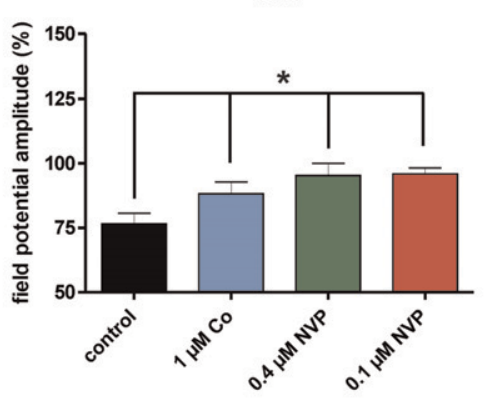

D

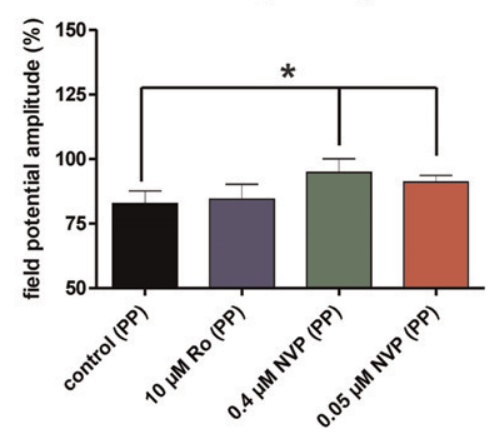

E

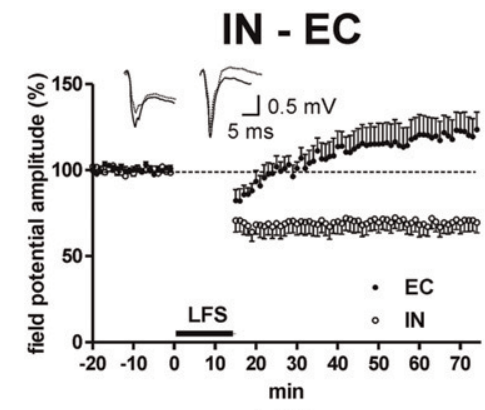

$\mathbf{F}$

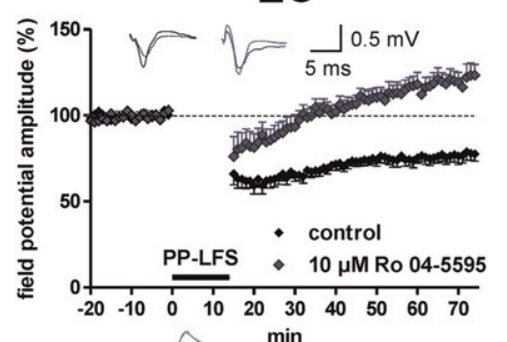

G

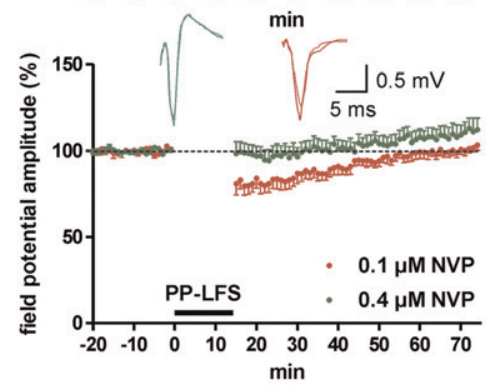

H

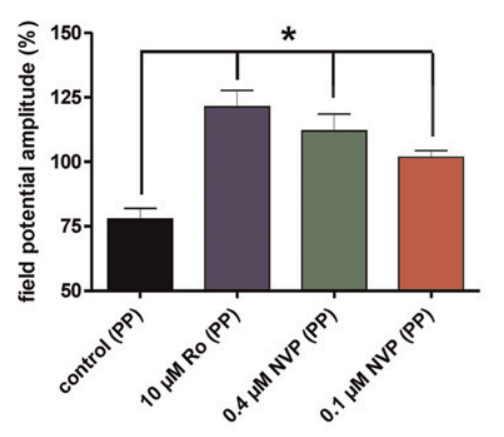

Figure 5. NR2A and NR2B subunits are involved in the induction of single and PP-LFS-induced LALTD. Recordings presented on the left were performed with stimulation of IN fibers. $(A)$ In the presence of the NR2B subunit antagonist Co 101244, LA-LTD was reduced in response to single LFS, when compared with drug-free controls. $(B)$ In the presence of the NR2A subunit antagonist NVP-AAM077 $(0.1 \mu \mathrm{M}$ or $0.4 \mu \mathrm{M})$. (C) LA-LTD induced by single-pulse LFS was abolished by NMDA subunit antagonists when compared with drug-free control recording. (D) Similar results were found when LTD was induced by paired-pulse LFS in control recordings. Bar histograms of data points as averaged 57 to $60 \mathrm{~min}$ after LFS and PP-LFS (PP-LFS with an interstimulus interval of $40 \mathrm{msec}$ ), respectively, and normalized with respect to baseline (mean \pm SEM). Significant differences are indicated. ${ }^{*} P<0.05$. $(D)$ After PP-LFS, stable LA-LTD was induced. In the presence of Ro 04-5595, a magnitude of LA-LTD was induced comparable to that obtained in controls. In the presence of $0.05 \mu \mathrm{M}$ NVP or $0.4 \mu \mathrm{M} N V P, L A$ LTD was weakened. (E) Alternating IN and EC stimulation was applied in the same slices. Single-pulse LFS of different inputs to LA neurons caused either LTD (IN) or late LTP (EC). (F-H) Further recordings on the right site were performed during stimulation of EC fibers. Low-frequency stimulation (LFS) was performed with paired pulses (PP). (F) In the presence of Ro 04-5595, LA-LTD was abolished, whereas in drug-free controls, a stable LA-LTD could be induced. $(G)$ In the presence of NVP, LA-LTD was also completely blocked. Data points represent averaged amplitudes (mean \pm SEM) normalized with respect to baseline values. Representative traces were recorded (solid lines) 5 min prior to LFS and (dashed lines) 60 min after tetanus in the lateral nucleus of the amygdala. $(H)$ Bar histogram of data points averaged 57 to 60 min after PP-LFS and normalized with respect to baseline (mean \pm SEM). Significant differences are indicated. ${ }^{*} P<0.05$.

(Dalby and Mody 2003; Lozovaya et al. 2004; Scimemi et al. 2004), these findings provide a novel mechanism for sharpening pattern storage in the neuronal network (Rusakov et al. 2004). Rusakov et al. (2004) propose that an elevation in ambient glutamate, released from multiple synapses and sensed by extrasynaptic NR2B-containing receptors, could trigger widespread LTD if accompanied by neuronal depolarization. However, in 6-10-wk-old mice, the immunogold electron-microscopic analysis revealed that NR2B-subunit-containing NMDA receptors in the LA were more abundantly localized on the synaptic site than the extrasynaptic site in the spine, as is the case for NR2A-subunit-containing ones (Miwa et al. 2008).

We used the PP facilitation protocol to examine the possible presynaptic mechanisms that are involved in the induction of LTD. In accordance with data from Lin et al. (2000), but in contrast to data from Wang and Gean (1999), we found that LA-LTD induced by intranuclear stimulation was accompanied by an enhancement in the PP ratio, indicating that LA-LTD results from a decrease in transmitter release probability. Because LA-LTD is also dependent on group II mGLURs (Heinbockel and Pape 2000; Kaschel et al. 2004), presynaptic involvement might be due to the stimulation of presynaptically located mGLURs, since NR2A- and NR2B-subunit antagonists did not change PP facilitation.

In summary, our results do not support the model that only NR2A-type NMDARs are responsible for LTP induction. Moreover, our data regarding LFS of IN fibers also cast doubt on the proposed preponderance of NR2B in LTD induction (Collingridge et al. 2004). Sufficient calcium entry during different induction protocols seems to be more important than the presence of a distinct NMDAR subtype. Thus, rather than resulting from exclusive roles of NMDAR subtypes, the synaptic-plasticity response in the amygdala appears to be directed by the pattern of synaptic activation and the inputs used, which recruit the major NMDAR subtypes to variable extents, and trigger distinct signaling cascades (Berberich et al. 2005, 2007).

\section{Materials and Methods}

\section{Animals}

We used adult male C57BL/6 mice (8-12 wk) for electrophysiological experiments. Animals were housed in standardized conditions with an artificial 12-h darklight cycle and a room temperature of 
IN

A

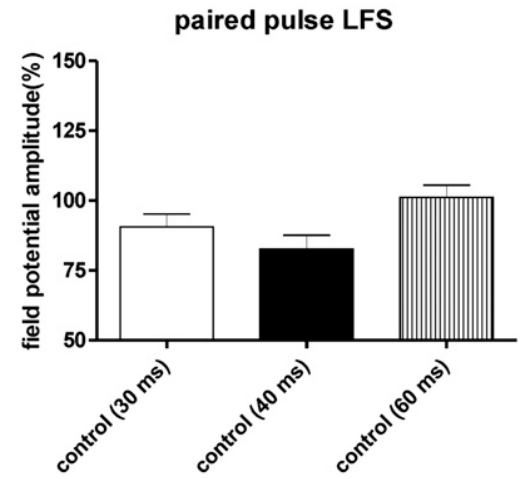

B

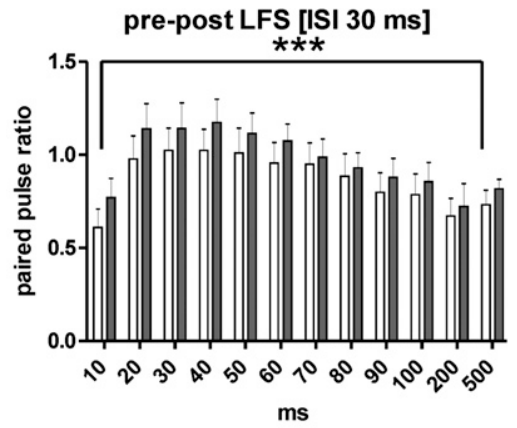

C

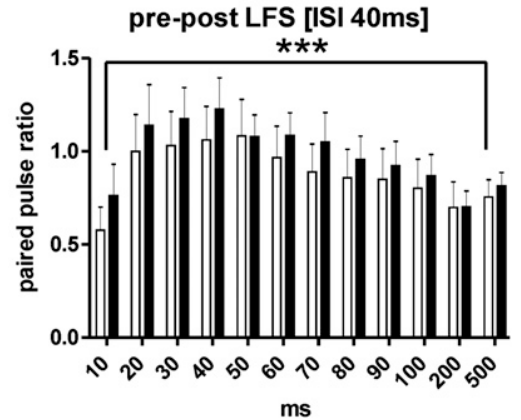

Figure 6. PPF increased after induction of LA-LTD. (A) Bar histogram of data points as averaged 57 to $60 \mathrm{~min}$ after PP-LFS with different interstimulus intervals and normalized with respect to baseline (mean \pm SEM). Induction of LTD was associated with an increase in PPF. $(B, C)$ PPF before (pre; open bars) and 60 min after (post; filled bars) PP-LFS-induced LTD. PP-LFS with an ISI of $30 \mathrm{msec}(B)$ and $40 \mathrm{msec}(C)$. The relationship of the second-response amplitude with respect to the first-response amplitude was calculated and plotted as a PP ratio against the interstimulus interval. $X$-axis, interstimulus interval; ${ }^{* * *} P<0.0005$ (Wilcoxon test); $\mathrm{IN}$, intranuclear stimulation.

$22^{\circ} \mathrm{C}$. Mice had free access to food and water. All of the experimental protocols were approved by government authorities and conformed to the European Communities Council Directive of November 24, 1986 (86/609/EEC).

\section{Preparation and recording}

Detailed methods for slice preparation have been previously described (Drephal et al. 2006). The positioning of the recording and stimulation electrodes is shown in Figure 1A. The mice were anesthetized and decapitated. For extracellular recordings, the brains were quickly removed and placed in ice-cold artificial cerebrospinal fluid (ACSF) $(129 \mathrm{mM} \mathrm{NaCl}, 3 \mathrm{mM} \mathrm{KCl}, 1.6 \mathrm{mM}$ $\mathrm{CaCl}_{2}, 1.8 \mathrm{mM} \mathrm{MgSO}_{4}, 1.25 \mathrm{mM} \mathrm{NaH}_{2} \mathrm{PO}_{4}, 10 \mathrm{mM}$ glucose, and $21 \mathrm{mM} \mathrm{NaHCO} 3)$. Hemisected horizontal slices $(400 \mu \mathrm{m})$ were prepared with a vibroslicer (Campden Instruments). Slices were placed in an interface chamber and allowed to equilibrate for 120 min at $35^{\circ} \mathrm{C}$. They were superfused continuously with ACSF $(1.5$ $\mathrm{mL} / \mathrm{min})$. The $\mathrm{pH}$ was maintained at $7.4\left(95 \% \mathrm{O}_{2}\right.$ and $\left.5 \% \mathrm{CO}_{2}\right)$.

Glass microelectrodes (Science Products) were filled with ACSF (tip resistance 1-3 M $\Omega$ ) and placed in the LA to record field potentials. Bipolar stimulation electrodes were used to stimulate either EC fibers or IN fibers or both.

\section{Stimulation parameters}

An input/output (I/O) response curve was constructed by varying the intensity of single-pulse stimulation and averaging six responses per intensity. The stimulus intensity that evoked a mean field potential equal to $50 \%$ of the maximum response was then used for all subsequent stimulations. To evaluate short-term synaptic interactions, we delivered paired-pulse (PP) stimuli with interstimulus intervals ranging from 10 to 500 msec. Six consecutive impulses were averaged off-line for each interval. The relative amplitude of the second response with respect to that of the first was calculated and plotted as the PP ratio against the interstimulus interval. Following PP stimulation, single stimuli were applied for at least $30 \mathrm{~min}$, and responses were monitored. Single stimuli (duration of $100 \mu \mathrm{sec}$ ) were presented every $10 \mathrm{sec}$. Once a stable baseline of responses was obtained for at least $20 \mathrm{~min}$, we either (1) recorded input/output curves and $\mathrm{PP}$ facilitation (PPF) in the presence of NR2A or NR2B subunit antagonists and then continued single-pulse stimulation for $15 \mathrm{~min}$; or (2) in drug-free conditions, directly delivered high-frequency stimulation (HFS) as two trains at $100 \mathrm{~Hz}$ (duration: $1 \mathrm{sec}, 30 \mathrm{sec}$ apart) or lowfrequency stimulation (LFS). The HFS paradigm has been chosen since theta burst stimulation did not produce consistent and reliable induction of LA-LTP. Different LFS protocols (single-pulse stimulation or PP stimulation [PP-LFS] with different interstimulus intervals; $1 \mathrm{~Hz}, 15 \mathrm{~min}$ ) were used to induce LTD. In some cases, we tried to record field potentials in the LA if single-pulse stimulation and LFS were alternatively applied either to EC or to afferents running through the LA (IN). Test stimulus pulses were applied alternately to IN and EC, with an interval of 5 or $10 \mathrm{sec}$ between an EC pulse and an IN pulse. However, in many slices, we detected either field potentials in response to EC stimulation or in response to intranuclear stimulation site. Therefore, not in all cases do both afferents converge at those LA neurons whose activity was recorded extracellularly. Drug-induced changes in baseline activity were considered. Subsequent responses to single stimuli were recorded for at least $60 \mathrm{~min}$, and their amplitudes were quantified as percent change with respect to baseline.

\section{Patch-clamp recordings}

Whole-cell recordings were performed under submerged recording conditions in horizontal slices $(300 \mu \mathrm{m})$ derived from 8-wkold mice. The internal patch solution contained $130 \mathrm{mM}$ Csgluconate, $8 \mathrm{mM} \mathrm{CsCl}, 10 \mathrm{mM}$ HEPES, $10 \mathrm{mM}$ EGTA, $2 \mathrm{mM} \mathrm{NaCl}$, and $2 \mathrm{mM}$ Mg-ATP (pH 7.3). Whole-cell recordings were made using a Multiclamp 700B (Axon Instruments, Molecular Devices) and standard techniques (Gebhardt and Cull-Candy 2006). Patch pipettes pulled from thick-walled borosilicate glass had a resistance of 6-8 $\mathrm{M} \Omega$ when filled with solution. LA projection neurons were identified visually. The access resistance was checked during the recording, and the experiments were stopped if the access resistance had changed more than 10\%. NMDAR-isolated evoked EPSCs were measured after EC stimulation. Data were recorded by Clampex 9 with a sampling rate of $10 \mathrm{kHz}$ and filtered at $2 \mathrm{kHz}$.

\section{Drug application}

All of the drugs were bath-applied at the indicated concentrations, starting at least $30 \mathrm{~min}$ before HFS or LFS and continuing throughout the train stimulation for a total period of 45-60 min. We alternated between control and treatment experiments 
to account for potential day-to-day and time-of-day differences. We used two different NR2B antagonists that were obtained from Tocris Bioscience. It is known that the Co 101244 hydrochloride (1-[2-(4hydroxy-phenoxy)-ethyl]-4-(4-methyl-benzyl)-piperidin-4-ol) $\mathrm{IC}_{50}$ values are $0.043 \mu \mathrm{M},>100 \mu \mathrm{M}$, and $>100 \mu \mathrm{M}$ for the NR1A/2B, $\mathrm{NR} 1 \mathrm{~A} / 2 \mathrm{~A}$, and NR1A/2C subunit combinations, respectively (alternative names: Ro 63-1908 and PD 174494). In addition, the NR2Bspecific antagonist Ro 04-5595 (1-[2-(4-chlorophenyl)ethyl]-1,2,3,4tetrahydro-6-methoxy-2-methyl-7-isoquino-linol hydrochloride; $K_{\mathrm{i}}=31 \mathrm{nM}$ ) was used. The NR2A-specific antagonist NVP-AAM077 ([R-[(S)-1-(4-bromo-phenyl)-ethylamino]-2,3-dioxo-1,2,3,4-tetrahydroquino-xalin-5-yl]-methyl)-phosphonic acid; NVP) was a kind gift from Novartis Pharma. NVP-AAM077 is $\sim 14$-fold selective for NR2A versus NR2B receptors against recombinant receptors in HEK293 cells (Bartlett et al. 2007). To separate the effects on NR2A from those on NR2B with regard to plasticity, we tested different concentrations $(0.05,0.1$, and $0.4 \mu \mathrm{M}$ NVP). Recent studies indicated that, at a high concentration $(0.4 \mu \mathrm{M})$, NVP-AAM077 also antagonizes NR2B-containing NMDA receptors (Berberich et al. 2005; Weitlauf et al. 2005; Frizelle et al. 2006), whereas considering the uncertainties of the concentrations of NVPAAM077 reaching synaptic sites, it can be suggested that at concentrations of 0.05 and $0.1 \mu \mathrm{M}$, NVP-AAM077 will block predominantly NR2A subunits (Bartlett et al. 2007; Wu et al. 2007). Ifenprodil hemitartrate $(10 \mu \mathrm{M}), \mathrm{CNQX}(10 \mu \mathrm{M}), \mathrm{APV}(50$ $\mu \mathrm{M})$, and bicuculline methochloride $(30 \mu \mathrm{M})$ were from Tocris.

\section{Data analysis}

Data were collected and averaged with the custom-made software Signal 2 (Cambridge Electronic Design). We defined the fieldpotential amplitude as the absolute DC voltage of a vertical line running from the minimal point of the field potential to its intersection with a line running tangential to the points of fieldpotential onset and offset. It is assumed that the recorded negative wave reflects a summation of both excitatory postsynaptic potentials (EPSPs) and synchronized action potentials (population spike component) (Watanabe et al. 1995; Doyere et al. 2003). We therefore analyzed the amplitude of field potentials in the present study. Additionally, the slope measure in the lateral amygdala is more sensitive to variability and signal noise, making it more difficult to analyze (Doyere et al. 2003).

Whole-cell recordings were analyzed with Clampfit 9. Data are given as mean \pm SEM.

Significance of differences within groups was calculated by Wilcoxon test. Significance of differences between groups was calculated by Mann-Whitney test (Software GraphPad Prism 5). $P$ $<0.05$ was considered to be significant. Analyses between the groups were performed for the whole input/output curves and for all intervals together after determination of PP ratios. To express and compare changes of field potential amplitudes between the animal groups, we averaged responses from the 57-60 min period after HFS or LFS.

\section{Acknowledgments}

We thank Roland Schneider for experimental help and Oliver von Bohlen und Halbach for providing the horizontal brain slice photography. We also thank Novartis Pharma AG (Basel, Switzerland) for providing NVP-AAM077.

\section{References}

Aroniadou-Anderjaska V, Post RM, Rogawski MA, Li H. 2001. Input-specific LTP and depotentiation in the basolateral amygdala. Neuroreport 12: 635-640.

Bartlett TE, Bannister NJ, Collett VJ, Dargan SL, Massey PV, Bortolotto ZA, Fitzjohn SM, Bashir ZI, Collingridge GL, Lodge D. 2007. Differential roles of NR2A and NR2B-containing NMDA receptors in LTP and LTD in the CA1 region of two-week old rat hippocampus. Neuropharmacology 52: 60-70.

Bauer EP, Schafe GE, LeDoux JE. 2002. NMDA receptors and L-type voltagegated calcium channels contribute to long-term potentiation and different components of fear memory formation in the lateral amygdala. J Neurosci 22: 5239-5249.

Berberich S, Punnakkal P, Jensen V, Pawlak V, Seeburg PH, Hvalby O, Kohr G. 2005. Lack of NMDA receptor subtype selectivity for hippocampal long-term potentiation. J Neurosci 25: 6907-6910.

Berberich S, Jensen V, Hvalby O, Seeburg PH, Kohr G. 2007. The role of NMDAR subtypes and charge transfer during hippocampal LTP induction. Neuropharmacology 52: 77-86.

Chapman PF, Bellavance LL. 1992. NMDA receptor-independent LTP in the amygdala. Synapse 11: 310-318.

Collingridge GL, Isaac JT, Wang YT. 2004. Receptor trafficking and synaptic plasticity. Nat Rev Neurosci 5: 952-962.

Cummings JA, Mulkey RM, Nicoll RA, Malenka RC. 1996. $\mathrm{Ca}^{2+}$ signaling requirements for long-term depression in the hippocampus. Neuron 16: $825-833$.

Dalby NO, Mody I. 2003. Activation of NMDA receptors in rat dentate gyrus granule cells by spontaneous and evoked transmitter release. $J$ Neurophysiol 90: 786-797.

Davis M, Whalen PJ. 2001. The amygdala: Vigilance and emotion. Mol Psychiatry 6: 13-34.

De Olmos JE, Alheid GF, Beltramino CA. 1985. Amygdala. In The rat nervous system (ed. G Paxinos),Vol. 1, pp. 223-334. Academic Press, Australia.

Diamond DM, Park CR, Campbell AM, Woodson JC. 2005. Competitive interactions between endogenous LTD and LTP in the hippocampus underlie the storage of emotional memories and stress-induced amnesia. Hippocampus 15: 1006-1025.

Dingledine R, Borges K, Bowie D, Traynelis SF. 1999. The glutamate receptor ion channels. Pharmacol Rev 51: 7-61.

Doyere V, Schafe GE, Sigurdsson T, LeDoux JE. 2003. Long-term potentiation in freely moving rats reveals asymmetries in thalamic and cortical inputs to the lateral amygdala. Eur J Neurosci 17: 2703-2715.

Drephal C, Schubert M, Albrecht D. 2006. Input-specific long-term potentiation in the rat lateral amygdala of horizontal slices. Neurobiol Learn Mem 85: 272-282.

Erreger K, Dravid SM, Banke TG, Wyllie DJ, Traynelis SF. 2005. Subunitspecific gating controls rat NR1/NR2A and NR1/NR2B NMDA channel kinetics and synaptic signalling profiles. J Physiol 563: 345-358.

Faber ES, Callister RJ, Sah P. 2001. Morphological and electrophysiological properties of principal neurons in the rat lateral amygdala in vitro. $J$ Neurophysiol 85: 714-723.

Faber ES, Delaney AJ, Sah P. 2005. SK channels regulate excitatory synaptic transmission and plasticity in the lateral amygdala. Nat Neurosci 8: 635641.

Farb CR, Aoki C, LeDoux JE. 1995. Differential localization of NMDA and AMPA receptor subunits in the lateral and basal nuclei of the amygdala: A light and electron microscopic study. J Comp Neurol 362: 86-108.

Fendt M, Schmid S. 2002. Metabotropic glutamate receptors are involved in amygdaloid plasticity. Eur J Neurosci 15: 1535-1541.

Frizelle PA, Chen PE, Wyllie DJ. 2006. Equilibrium constants for (R)-[(S)-1(4-bromo-phenyl)-ethylamino]-(2,3-dioxo-1,2,3,4-tetrahydroquino xalin-5-yl)-methyl]-phosphonic acid (NVP-AAM077) acting at recombinant NR1/NR2A and NR1/NR2B N-methyl-D-aspartate receptors: Implications for studies of synaptic transmission. Mol Pharmacol 70: 1022-1032.

Gean P-W, Chang F-C, Huang C-C, Lin J-H, Way L-J. 1993. Long-term enhancement of EPSP and NMDA receptor-mediated synaptic transmission in the amygdala. Brain Res Bull 31: 7-11.

Gebhardt C, Cull-Candy SG. 2006. Influence of agonist concentration on AMPA and kainate channels in CA1 pyramidal cells in rat hippocampal slices. J Physiol 573: 371-394.

Heinbockel T, Pape HC. 2000. Input-specific long-term depression in the lateral amygdala evoked by theta frequency stimulation. J Neurosci 20: RC68.

Huang YY, Kandel ER. 1998. Postsynaptic induction and PKA-dependent expression of LTP in the lateral amygdala. Neuron 21: 169-178.

Huang YY, Kandel ER. 2007. Low-frequency stimulation induces a pathwayspecific late phase of LTP in the amygdala that is mediated by PKA and dependent on protein synthesis. Learn Mem 14: 497-503.

Humeau Y, Shaban H, Bissiere S, Luthi A. 2003. Presynaptic induction of heterosynaptic associative plasticity in the mammalian brain. Nature 426: 841-845.

Johnson LR, Hou M, Ponce-Alvarez A, Gribelyuk LM, Alphs HH, Albert L, Brown BL, LeDoux JE, Doyere V. 2008. A recurrent network in the lateral amygdala: A mechanism for coincidence detection. Front Neural Circuits 2: 3. doi: 10.3389/neuro.04.003.2008.

Johnston D, Wu SMS. 1995. Foundations of cellular neurophysiology. MIT Press, Cambridge.

Kaschel T, Schubert M, Albrecht D. 2004. Long-term depression in horizontal slices of the rat lateral amygdala. Synapse 53: 141-150.

Kemp N, Bashir ZI. 1999. Induction of LTD in the adult hippocampus by the synaptic activation of AMPA/kainate and metabotropic glutamate receptors. Neuropharmacology 38: 495-504. 
Kiyama Y, Manabe T, Sakimura K, Kawakami F, Mori H, Mishina M. 1998. Increased thresholds for long-term potentiation and contextual learning in mice lacking the NMDA-type glutamate receptor epsilon1 subunit. J Neurosci 18: 6704-6712.

Kohr G, Jensen V, Koester HJ, Mihaljevic AL, Utvik JK, Kvello A, Ottersen OP Seeburg PH, Sprengel R, Hvalby O. 2003. Intracellular domains of NMDA receptor subtypes are determinants for long-term potentiation induction. J Neurosci 23: 10791-10799.

Kutsuwada T, Kashiwabuchi N, Mori H, Sakimura K, Kushiya E, Araki K, Meguro H, Masaki H, Kumanishi T, Arakawa M. 1992. Molecular diversity of the NMDA receptor channel. Nature 358: 36-41.

Lamprecht R, Margulies DS, Farb CR, Hou M, Johnson LR, LeDoux JE. 2006. Myosin light chain kinase regulates synaptic plasticity and fear learning in the lateral amygdala. Neuroscience 139: 821-829.

LeDoux JE. 2000. Emotion circuits in the brain. Annu Rev Neurosci 23: 155 184.

Lee O, Lee CJ, Choi S. 2002. Induction mechanisms for L-LTP at thalamic input synapses to the lateral amygdala: Requirement of mGluR5 activation. Neuroreport 13: 685-691.

Li H, Weiss SR, Chuang DM, Post RM, Rogawski MA. 1998. Bidirectional synaptic plasticity in the rat basolateral amygdala: Characterization of an activity-dependent switch sensitive to the presynaptic metabotropic glutamate receptor antagonist $2 S$ - $\alpha$-ethylglutamic acid. J Neurosci 18: 1662-1670.

Lin HC, Wang SJ, Luo MZ, Gean PW. 2000. Activation of group II metabotropic glutamate receptors induces long-term depression of synaptic transmission in the rat amygdala. J Neurosci 20: 9017-9024.

Liu L, Wong TP, Pozza MF, Lingenhoehl K, Wang Y, Sheng M, Auberson YP, Wang YT. 2004. Role of NMDA receptor subtypes in governing the direction of hippocampal synaptic plasticity. Science 304: 10211024.

Logothetis NK, Wandell BA. 2004. Interpreting the BOLD signal. Annu Rev Physiol 66: 735-769

Lozovaya NA, Grebenyuk SE, Tsintsadze TS, Feng B, Monaghan DT, Krishtal OA. 2004. Extrasynaptic NR2B and NR2D subunits of NMDA receptors shape 'superslow' afterburst EPSC in rat hippocampus. J Physiol 558: 451-463.

Mahanty NK, Sah P. 1999. Excitatory synaptic inputs to pyramidal neurons of the lateral amygdala. Eur I Neurosci 11: 1217-1222.

Maren S. 2005. Synaptic mechanisms of associative memory in the amygdala. Neuron 47: 783-786.

Massey PV, Johnson BE, Moult PR, Auberson YP, Brown MW, Molnar E, Collingridge GL, Bashir ZI. 2004. Differential roles of NR2A and NR2Bcontaining NMDA receptors in cortical long-term potentiation and long-term depression. J Neurosci 24: 7821-7828.

McDonald AJ. 1984. Neuronal organization of the lateral and basolateral amygdaloid nuclei in the rat. J Comp Neurol 222: 589-606.

McKernan MG, Shinnick-Gallagher P. 1997. Fear conditioning induces a lasting potentiation of synaptic currents in vitro. Nature 390: 607611.

Miwa H, Fukaya M, Watabe AM, Watanabe M, Manabe T. 2008. Functional contributions of synaptically localized NR2B subunits of the NMDA receptor to synaptic transmission and long-term potentiation in the adult mouse CNS. J Physiol 586: 2539-2550.

Monyer H, Burnashev N, Laurie DJ, Sakmann B, Seeburg PH. 1994. Developmental and regional expression in the rat brain and functional properties of four NMDA receptors. Neuron 12: 529-540.

Nishiyama M, Hong K, Mikoshiba K, Poo MM, Kato K. 2000. Calcium stores regulate the polarity and input specificity of synaptic modification. Nature 408: $584-588$.

Norris CM, Korol DL, Foster TC. 1996. Increased susceptibility to induction of long-term depression and long-term potentiation reversal during aging. I Neurosci 16: 5382-5392.

Pitkaenen A, Savander V, LeDoux JE. 1997. Organization of intraamygdaloid circuitries in the rat: An emerging framework for understanding functions of the amygdala. Trends Neurosci 20: 517-523.

Pitkanen A, Savander M, Nurminen N, Ylinen A. 2003. Intrinsic synaptic circuitry of the amygdala. Ann N Y Acad Sci 985: 34-49.

Rammes G, Steckler T, Kresse A, Schutz G, Zieglgansberger W, Lutz B. 2000 Synaptic plasticity in the basolateral amygdala in transgenic mice expressing dominant-negative cAMP response element-binding protein (CREB) in forebrain. Eur J Neurosci 12: 2534-2546.

Rodrigues SM, Schafe GE, LeDoux JE. 2001. Intra-amygdala blockade of the NR2B subunit of the NMDA receptor disrupts the acquisition but not the expression of fear conditioning. J Neurosci 21: 6889-6896.

Rogan MT, Staubli UV, LeDoux JE. 1997. Fear conditioning induces associative long-term potentiation in the amygdala. Nature 390: 604 607.

Royer S, Pare D. 2003. Conservation of total synaptic weight through balanced synaptic depression and potentiation. Nature 422: 518-522.

Rusakov DA, Scimemi A, Walker MC, Kullmann DM. 2004. Comment on Role of NMDA receptor subtypes in governing the direction of hippocampal synaptic plasticity. Science 305: 1912. doi: 10.1126/ science. 1101128 .

Sakimura K, Kutsuwada T, Ito I, Manabe T, Takayama C, Kushiya E, Yagi T, Aizawa S, Inoue Y, Sugiyama H, et al. 1995. Reduced hippocampal LTP and spatial learning in mice lacking NMDA receptor epsilon 1 subunit. Nature 373: 151-155.

Samson RD, Pare D. 2006. A spatially structured network of inhibitory and excitatory connections directs impulse traffic within the lateral amygdala. Neuroscience 141: 1599-1609.

Samson RD, Dumont EC, Pare D. 2003. Feedback inhibition defines transverse processing modules in the lateral amygdala. J Neurosci 23: 1966-1973.

Schafe GE, Atkins CM, Swank MW, Bauer EP, Sweatt JD, LeDoux JE. 2000. Activation of ERK/MAP kinase in the amygdala is required for memory consolidation of Pavlovian fear conditioning. J Neurosci 20: 8177 8187.

Schroeder BW, Shinnick-Gallagher P. 2004. Fear memories induce a switch in stimulus response and signaling mechanisms for long-term potentiation in the lateral amygdala. Eur J Neurosci 20: 549-556.

Schubert M, Albrecht D. 2008. Activation of kainate GLU(K5) transmission rescues kindling-induced impairment of LTP in the rat lateral amygdala. Neuropsychopharmacology 33: 2524-2535.

Schubert M, Siegmund H, Pape HC, Albrecht D. 2005. Kindling-induced changes in plasticity of the rat amygdala and hippocampus. Learn Mem 12: $520-526$

Scimemi A, Fine A, Kullmann DM, Rusakov DA. 2004. NR2B-containing receptors mediate cross talk among hippocampal synapses. J Neurosci 24: $4767-4777$.

Shin RM, Tsvetkov E, Bolshakov VY. 2006. Spatiotemporal asymmetry of associative synaptic plasticity in fear conditioning pathways. Neuron 52: $883-896$.

Sigurdsson T, Doyere V, Cain CK, LeDoux JE. 2007. Long-term potentiation in the amygdala: A cellular mechanism of fear learning and memory. Neuropharmacology 52: 215-227.

Swanson LW, Petrovich GD. 1998. What is the amygdala? Trends Neurosci 21: $323-331$.

Szinyei C, Stork O, Pape HC. 2003. Contribution of NR2B subunits to synaptic transmission in amygdaloid interneurons. J Neurosci 23: 25492556.

Tang YP, Shimizu E, Dube GR, Rampon C, Kerchner GA, Zhuo M, Liu G, Tsien JZ. 1999. Genetic enhancement of learning and memory in mice. Nature 401: 63-69.

Tchekalarova J, Albrecht D. 2007. Angiotensin II suppresses long-term depression in the lateral amygdala of mice via L-type calcium channels. Neurosci Lett 415: 68-72.

Toyoda H, Zhao MG, Zhuo M. 2005. Roles of NMDA receptor NR2A and NR2B subtypes for long-term depression in the anterior cingulate cortex. Eur J Neurosci 22: 485-494.

Tsvetkov E, Carlezon WA, Benes FM, Kandel ER, Bolshakov VY. 2002. Fear conditioning occludes LTP-induced presynaptic enhancement of synaptic transmission in the cortical pathway to the lateral amygdala. Neuron 34: 289-300.

von Bohlen und Halbach O, Albrecht D. 1998a. Angiotensin II inhibits long-term potentiation within the lateral nucleus of the amygdala through AT1 receptors. Peptides 19: 1031-1036.

von Bohlen und Halbach O, Albrecht D. 1998b. Tracing of axonal connectivities in a combined slice preparation of rat brains-a study by rhodamine-dextran-amine-application in the lateral nucleus of the amygdala. J Neurosci Methods 81: 169-175.

von Bohlen und Halbach O, Albrecht D. 2002. Reciprocal connections of the hippocampal area CA1, the lateral nucleus of the amygdala and cortical areas in a combined horizontal slice preparation. Neurosci Res 44: $91-100$

Wagner JJ, Alger BE. 1995. GABAergic and developmental influences on homosynaptic LTD and depotentiation in rat hippocampus. J Neurosci 15: $1577-1586$.

Walker DL, Davis M. 2008. Amygdala infusions of an NR2B-selective or an NR2A-preferring NMDA receptor antagonist differentially influence fear conditioning and expression in the fear-potentiated startle test. Learn Mem 15: 67-74

Wang SJ, Gean PW. 1999. Long-term depression of excitatory synaptic transmission in the rat amygdala. J Neurosci 19: 10656-10663.

Watanabe Y, Ikegaya Y, Saito H, Abe K. 1995. Roles of GABAA, NMDA and muscarinic receptors in induction of long-term potentiation in the medial and lateral amygdala in vitro. Neurosci Res 21: 317-322.

Weisskopf MG, LeDoux JE. 1999. Distinct populations of NMDA receptors at subcortical and cortical inputs to principal cells of the lateral amygdala. J Neurophysiol 81: 930-934.

Weisskopf MG, Bauer EP, LeDoux JE. 1999. L-type voltage-gated calcium channels mediate NMDA-independent associative long-term potentiation at thalamic input synapses to the amygdala. J Neurosci 19: 10512-10519. 
Weitlauf C, Honse Y, Auberson YP, Mishina M, Lovinger DM, Winder DG. 2005. Activation of NR2A-containing NMDA receptors is not obligatory for NMDA receptor-dependent long-term potentiation. J Neurosci 25: 8386-8390.

Wong RW, Setou M, Teng J, Takei Y, Hirokawa N. 2002. Overexpression of motor protein KIF17 enhances spatial and working memory in transgenic mice. Proc Natl Acad Sci 99: 14500-14505.

Wu LJ, Xu H, Ren M, Cao X, Zhuo M. 2007. Pharmacological isolation of postsynaptic currents mediated by NR2A- and NR2B-containing NMDA receptors in the anterior cingulate cortex. Mol Pain 3: 11. doi: 10.1186/ 1744-8069-3-11.
Zhao MG, Toyoda H, Lee YS, Wu LJ, Ko SW, Zhang XH, Jia Y, Shum F, Xu H, Li BM, et al. 2005. Roles of NMDA NR2B subtype receptor in prefrontal long-term potentiation and contextual fear memory. Neuron 47: 859872 .

Zinebi F, Russell RT, McKernan M, Shinnick-Gallagher P. 2001. Comparison of paired-pulse facilitation of AMPA and NMDA synaptic currents in the lateral amygdala. Synapse 42: 115-127.

Received March 4, 2009; accepted in revised form March 31, 2009. 


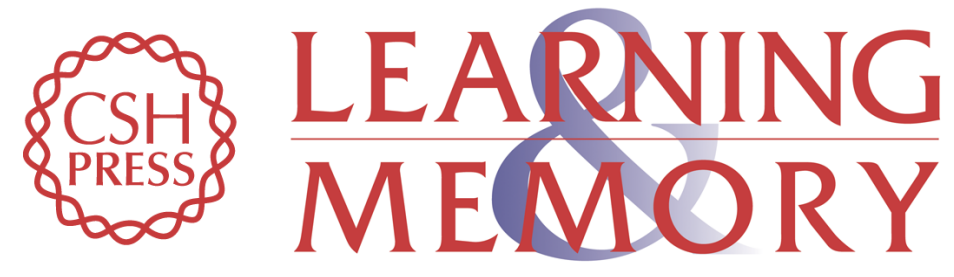

\section{Both NR2A and NR2B subunits of the NMDA receptor are critical for long-term potentiation and long-term depression in the lateral amygdala of horizontal slices of adult mice}

Tobias Müller, Doris Albrecht and Christine Gebhardt

Learn. Mem. 2009, 16:

Access the most recent version at doi:10.1101/lm.1398709

References This article cites 87 articles, 25 of which can be accessed free at: http://learnmem.cshlp.org/content/16/6/395.full.html\#ref-list-1

License

Email Alerting

Receive free email alerts when new articles cite this article - sign up in the box at the Service top right corner of the article or click here. 